\title{
HOLD-TIME EFFECTS ON LOW-CYCLE-FATIGUE BEHAVIOR OF HASTELLOY® X SUPERALLOY AT HIGH TEMPERATURES
}

\author{
Y. L. Lu, L. J. Chen*, G.Y. Wang, M. L. Benson, and P. K. Liaw \\ Department of Materials Science and Engineering \\ The University of Tennessee \\ Knoxville, TN 37996-2200
}

S. A. Thompson, J. W. Blust, P. F. Browning, A.K. Bhattacharya, and J.M. Aurrecoechea

Solar Turbines Inc.

2200 Pacific Highway, P. O. Box 85376, MZ R-1

San Diego, CA 92186-5376

and

D. L. Klarstrom

Haynes International, Inc.

1020 West Park Avenue, P. O. Box 9013

Kokomo, IN 46904-9013

Keywords: Nickel-Base Superalloy; Low-Cycle Fatigue; Hold-Time Effect; Fatigue-Life Prediction

\begin{abstract}
Total strain-controlled low-cycle-fatigue tests with and without hold times were performed at temperatures ranging from $816^{\circ} \mathrm{C}$ to $982^{\circ} \mathrm{C}$ in a laboratory air on a nickel-based superalloy, HASTELLOY X. The influence of hold times on the cyclicstress response and fatigue life was studied. At the temperatures considered, the alloy exhibited initial cyclic hardening, followed by a saturated cyclic-stress response or cyclic softening under low-cycle fatigue without hold times. For low-cycle-fatigue tests with hold times, however, the alloy showed cyclic hardening, cyclic stability, or cyclic softening, which is closely related to the test temperature and the duration of the hold time. It was also observed that the low-cycle-fatigue life of the alloy considerably decreased due to the introduction of strain hold times. Generally, a longer hold time would result in a greater reduction in the fatigue life. For the tests without hold times, the test temperature seems to have little influence on the fatigue life of the alloy at the test temperatures from $816^{\circ} \mathrm{C}$ to $927^{\circ} \mathrm{C}$. However, when the test temperature increased to $982^{\circ} \mathrm{C}$, the fatigue life clearly shortened. In addition, the fracture surfaces of the fatigued specimens were observed, using scanningelectron microscopy, to determine the crack initiation and propagation modes. The fatigue life was predicted by the frequency-modified tensile-hysteresis-energy method. The predicted lives were found to be in good agreement with the experiment results.
\end{abstract}

\section{Introduction}

A solid-solution-strengthened nickel-based superalloy, HASTELLOY $\mathrm{X}$, is currently used in gas-turbine engines for combustion zone components, such as transition ducts, combustor cans, spray bars, and flame holders, as well as for afterburners, tailpipes, and cabin heaters. Moreover, the HASTELLOY $\mathrm{X}$ is also used in the chemical-process industry for retorts muffles, catalyst-support grids, furnace baffles, tubing for pyrolysis operations, and flash-drier components. The wide usage of this material in gas-turbine and chemical-process industries is based on an exceptional combination of its hightemperature strength, excellent forming and welding characteristics, and good resistance to oxidation and stresscorrosion cracking. It is expected that the damage from lowcycle fatigue, creep, environment and even their interaction will be the main limiting factors of their service lifetimes at elevated temperatures. Thus, it is very important to investigate the hightemperature, low-cycle fatigue behavior of the HASTELLOY X alloy for safely designing the high-temperature components and finding the potential usage of the alloy.

Klarstrom and Lai [1] had examined the effects of thermal aging on the low-cycle fatigue behavior of HASTELLOY X and found that the fatigue life was degraded by the aging treatment at $760^{\circ} \mathrm{C}$ for 1,000 Hours. They suggested that the cause of the fatigue-life degradation was the precipitation of the sigma-phase and $\mathrm{M}_{23} \mathrm{C}_{6}$ carbides after long-term aging. Miner and Castelli [2] studied the cyclic-hardening mechanism of HASTELLOY $\mathrm{X}$ during isothermal and thermomechanical cyclic deformation, and observed that the alloy exhibited a broad peak in cyclic 
hardening between about $200^{\circ} \mathrm{C}$ and $700^{\circ} \mathrm{C}$, with a maximum increase in the cyclic stress amplitude around $500^{\circ} \mathrm{C}$. They proposed that the precipitation of $\mathrm{M}_{23} \mathrm{C}_{6}$ on the dislocations and solute drag could be attributed to cyclic hardening. In his research concerning the hold-time effect on low-cycle fatigue at $704^{\circ} \mathrm{C}$ in air, Seaver [3] pointed out that both tension and compression hold times resulted in a substantial life reduction, but the compression hold time was potentially more damaging in the low strain regime because of the development of high tensile mean stresses. This author thought that a contributing cause of the hold-time effect should be an aging reaction that occurred in HASTELLOY X. Tsuji and Kondo [4] studied the effects of cyclic frequency, strain waveform, and hold time on low-cycle fatigue behavior of HASTELLOY $\mathrm{X}$ and its modified version, HASTELLOY $\mathrm{XR}$, at $900^{\circ} \mathrm{C}$ in a helium environment. These authors found that decreasing the cyclic frequency would lead to a notable reduction in the fatigue life. In their tests with different holding types of trapezoidal strain waveforms, the reduction in the fatigue life was found to be the most significant in the tests with tensile hold times, and more effective than in the tests with symmetric hold times, while no appreciable fatigue life reduction was recognized in the tests with compressive hold times. They suggested that creep damage could be attributed to a considerable reduction of the fatigue life in the tests at lower cyclic frequencies and with hold times. In their study on fatiguecrack-growth behavior of HASTELLOY X at $650^{\circ} \mathrm{C}$, Hour and Stubbins [5] observed that the alloy remained a transgranular crack-propagation mode at all frequencies.

The purpose of this investigation is to present experimental results and theoretical analyses of the test-temperature and tensile strain hold-time effects on low-cycle fatigue behavior of HASTELLOY $X$ at elevated temperatures in air. At the same time, life prediction is also conducted using the frequencymodified tensile hysteresis energy methods.

\section{Test Material and Procedures}

The HASTELLOY $\mathrm{X}$ alloy was supplied by Haynes International, Inc. and received in a solid-solution annealed condition. The final heat treatment is annealing at $1,175^{\circ} \mathrm{C}$, followed by a rapid air-cooling to room temperature. Sheet materials with a thickness of $3.2 \mathrm{~mm}$ from three different heats (heats A, B, and C) were used. The microstructure of the asreceived material is shown in Figure 1. It can be noted that the alloy consists predominately of equiaxial austenitic grains with some annealing twins. The alloy after solution annealing had an average grain diameter of about $90 \mu \mathrm{m}$. In addition, a small amount of second-phase particles can be also observed, which has been determined to be $\mathrm{M}_{6} \mathrm{C}$ carbides in which $\mathrm{M}$ is primarily molybdenum [6]. The nominal chemical composition is given in Table 1 .

The geometry of the low-cycle fatigue specimens is shown in Figure 2. The specimen was rectangular, with a gage length of $12.8 \mathrm{~mm}$, a width of $6.4 \mathrm{~mm}$, and a thickness of $3.2 \mathrm{~mm}$. Fully reversed pull-push low-cycle fatigue tests with and without hold times were performed in laboratory air, employing a computercontrolled Material Test System (MTS) servohydraulic-testing machine. A resistance furnace was employed to heat the specimens. The temperature control was accomplished, using two thermocouples spot-welded on the specimen surface outside

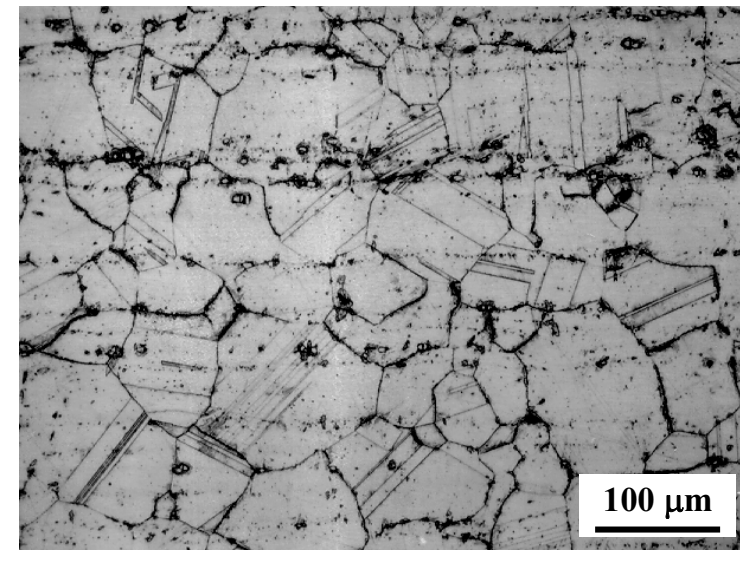

Figure 1. The microstructure of the HASTELLOY X alloy in the as-received condition.

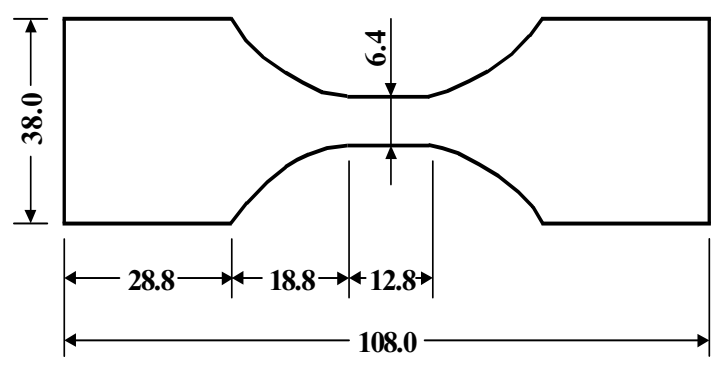

Figure 2. Geometry of the low-cycle fatigue specimen (mm).

the gage length. The fluctuation of the test temperature along the gage section of the specimens was at least maintained within a range of $\pm 2{ }^{\circ} \mathrm{C}$. An axial total strain-range control mode was applied. A high-temperature extensometer was used to measure and monitor the axial strain. The extensometer was springloaded, and had two ceramic legs, which were in direct contact with the gage-length area of the specimen. Forced air was used for cooling the extensometer during high-temperature, low-cycle fatigue testing.

For the high-temperature, low-cycle fatigue tests with no hold time, a cyclic frequency of $1 \mathrm{~Hz}$ was used, and the imposed axial total strain range was varied in the range of 0.4 to $2.0 \%$. In the case of hold-time tests, a hold time of $2 \mathrm{~min}$., $10 \mathrm{~min}$., or 60 min. was introduced at the maximum tensile strain of each cycle. All tests were run to failure, i.e., the final separation of the specimen. Most of the tests were conducted, using specimens made from heat A materials. Tests without hold time and with $10 \mathrm{~min}$. hold at temperatures $816^{\circ} \mathrm{C}$ and $927^{\circ} \mathrm{C}$ were repeated, using specimens made from heats $\mathrm{B}$ and $\mathrm{C}$ materials.

The fracture surface of some specimens subjected to low-cycle fatigue tests with and without hold times were examined, using a Cambridge S-320 scanning-electron microscope (SEM) in order to determine the crack initiation and propagation mode. 
Table 1. The nominal chemical composition of HASTELLOY X (in weight percent)

\begin{tabular}{ccccccccc}
\hline $\mathrm{Ni}$ & $\mathrm{Cr}$ & $\mathrm{Co}$ & $\mathrm{Mo}$ & $\mathrm{W}$ & $\mathrm{Fe}$ & $\mathrm{Si}$ & $\mathrm{Mn}$ & $\mathrm{C}$ \\
\hline Bal. & 22.5 & 1.0 & 9.0 & 0.6 & 18.5 & 0.4 & 0.8 & 0.07 \\
\hline
\end{tabular}
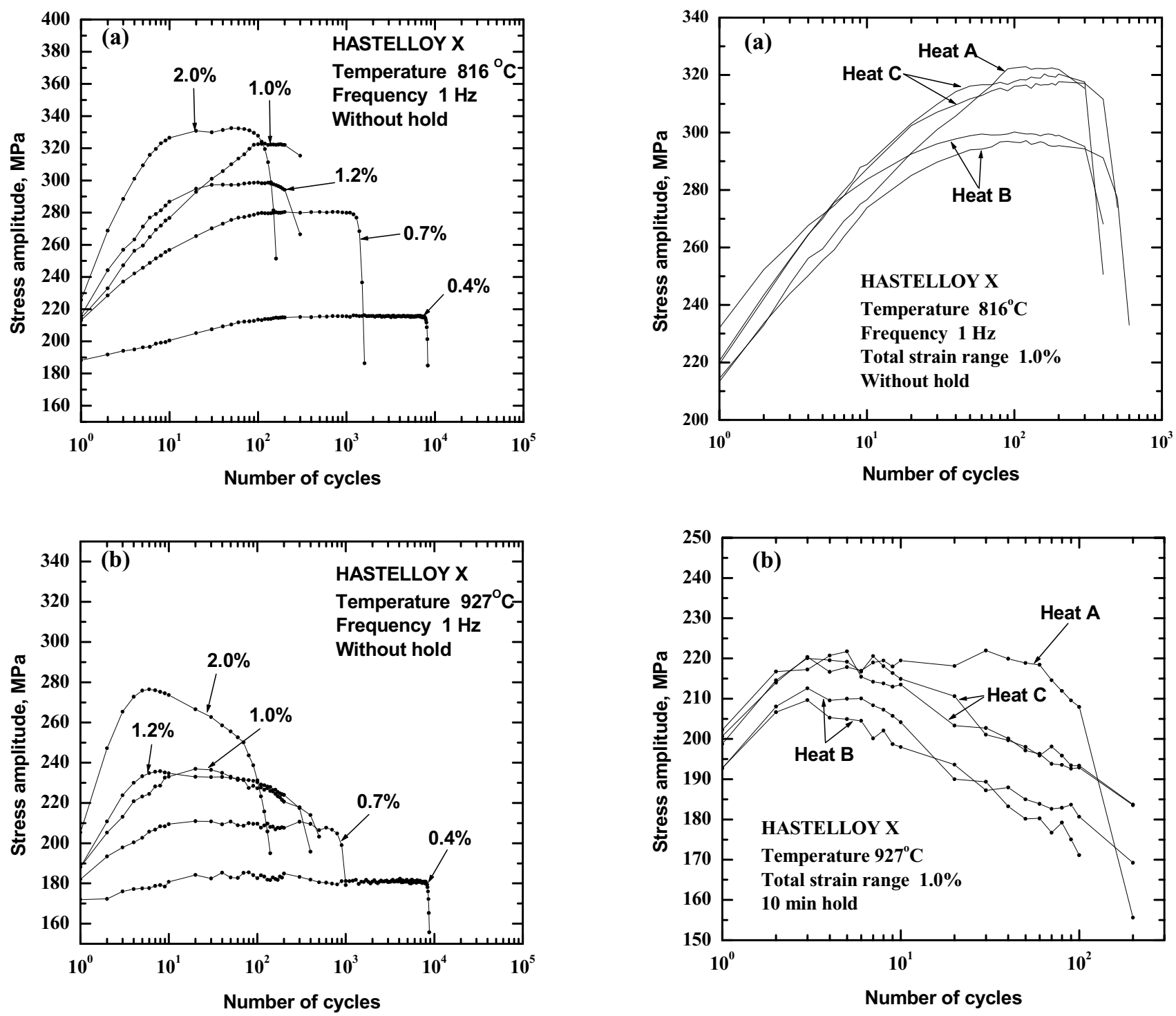

Figure 3. Cyclic-stress responses of tests without hold time at various total strain ranges for HASTELLOY X (heat A) at $816^{\circ} \mathrm{C}$ (a) and $927^{\circ} \mathrm{C}(\mathrm{b})$.

\section{Results and Discussions}

\section{$\underline{\text { Stress Response during Cyclic Loading }}$}

Figure 4. Heat-to-heat variation in the cyclic-stress responses: (a) $816^{\circ} \mathrm{C}, 1.0 \%$ total-strain range, without hold time; (b) $927^{\circ} \mathrm{C}, 1.0 \%$ total-strain range, $10 \mathrm{~min}$. hold time.

The cyclic stress responses are obtained by plotting the tensile peak stresses from the hysteresis loops against the respective number of cycles. The cyclic stress responses at various strain levels without hold time for both test temperatures of $816^{\circ} \mathrm{C}$ and $927^{\circ} \mathrm{C}$ and are shown in Figures $3 \mathrm{a}$ and $3 \mathrm{~b}$, respectively. It can be seen that the cyclic-stress-response behavior is dependent on the test temperature and imposed total strain range. At $816^{\circ} \mathrm{C}$ 


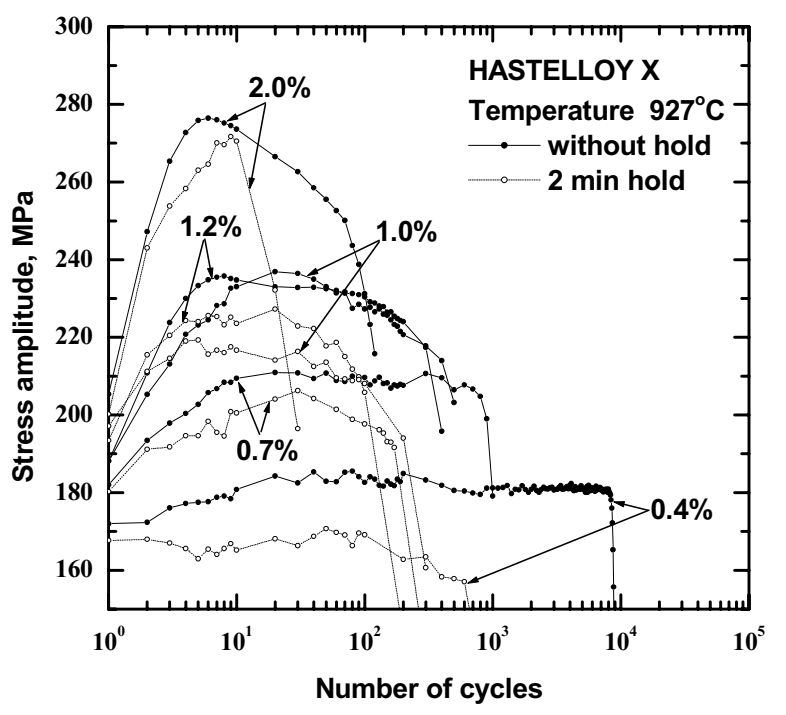

Figure 5. Effect of 2 min hold time at the maximum strain on the cyclic stress response for tests with various total strain ranges at $927^{\circ} \mathrm{C}$ (heat A).

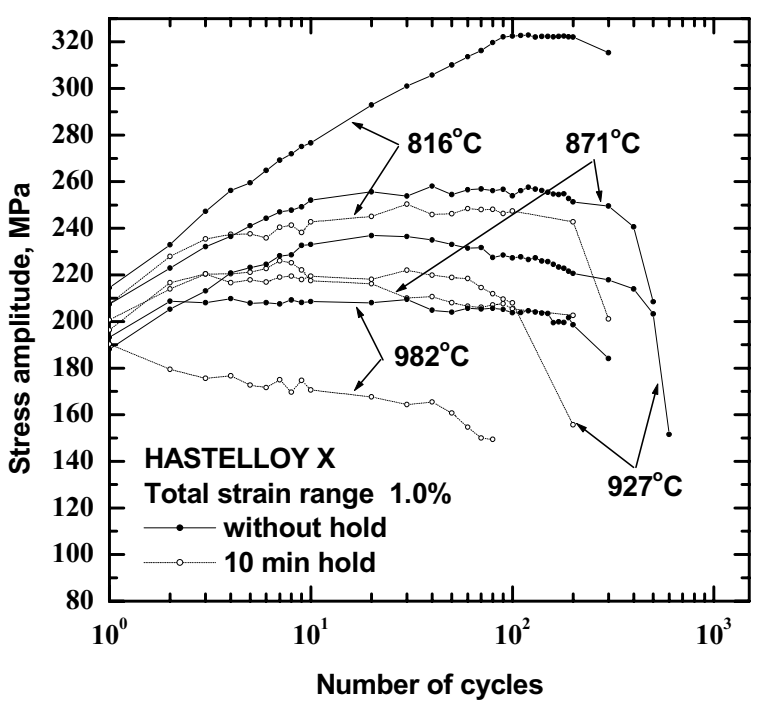

Figure 7. Effect of temperature and $10 \mathrm{~min}$. hold time on the cyclic-stress response at a total strain range of $1.0 \%$ (heat $\mathrm{A}$ ).

and under all total strain ranges, the alloy exhibits an initial cyclic hardening to the peak stress amplitude, followed by a saturated stress-response behavior until the final drop in the cyclic-stress amplitude due to the initiation and propagation of fatigue cracks. At $927^{\circ} \mathrm{C}$, if the lower total strain ranges are applied, the cyclic-stress-response behavior similar to that at $816^{\circ} \mathrm{C}$ is observed. However, if the total strain ranges are higher $(\geq 0.7 \%$ ), the alloy shows a softening regime after hardening in the early stage, and there is no stress saturation. In general, the
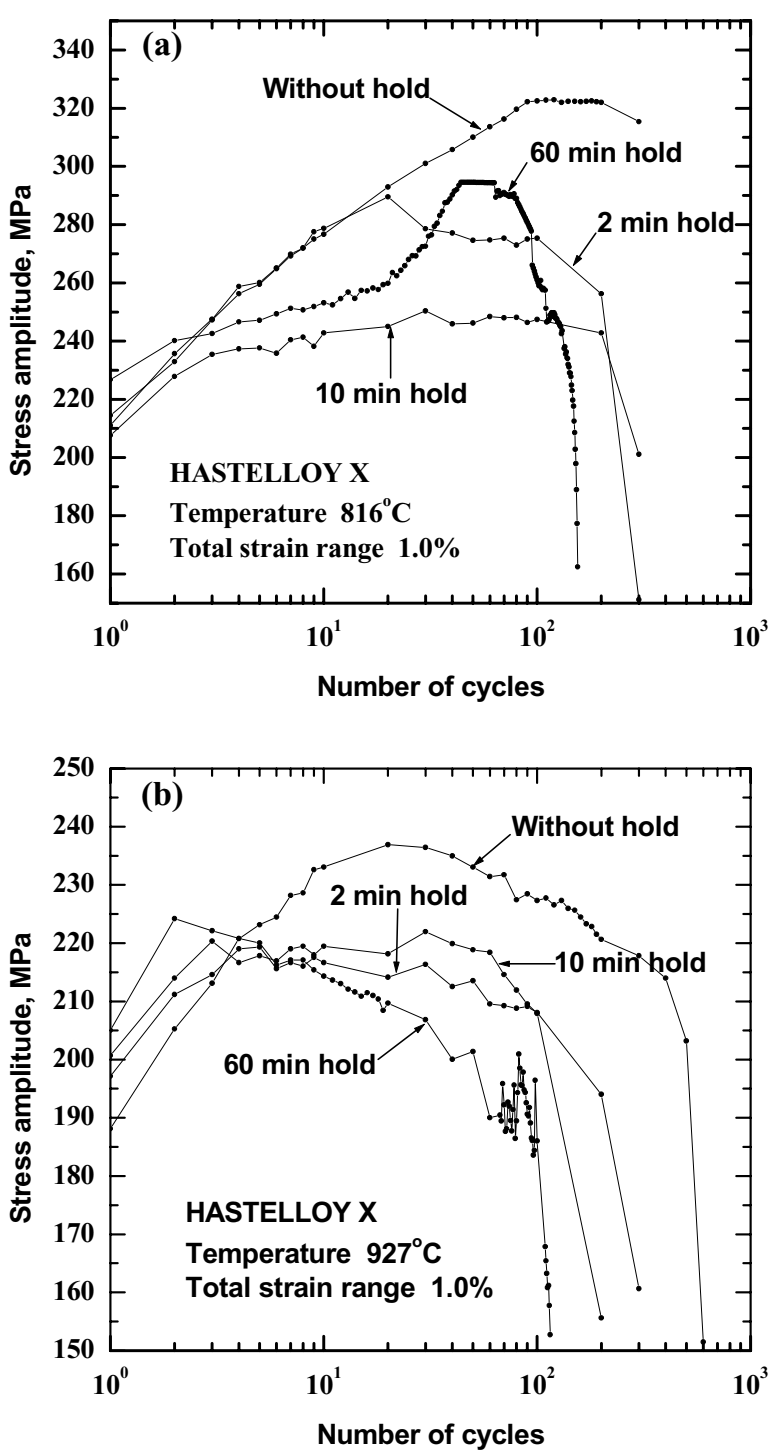

Figure 6. Effect of increasing hold time on the cyclicstress response at the total-strain range of $1.0 \%$ at $816^{\circ} \mathrm{C}$ (a) and $927^{\circ} \mathrm{C}$ (b) (heat A).

degree of both cyclic strain hardening and softening increases with increasing the total strain range. However, the cyclic-stress response at the $1.0 \%$ total strain range is unique in that its peak stress amplitude is either higher than $\left(\right.$ at $\left.816^{\circ} \mathrm{C}\right)$ or the same as (at $927^{\circ} \mathrm{C}$ ) that at $1.2 \%$ total strain range.

Figure 4 presents the heat-to-heat variation in the cyclic-stress responses. Tests considered are those with a total strain range of $1.0 \%$, and without hold time at $816^{\circ} \mathrm{C}$ (Fig. 4a) and with a 10 min. hold time at $927^{\circ} \mathrm{C}$ (Fig. 4b). The stress amplitude at the near-start region could occasionally be influenced by the specimen-to-specimen variation (compare the two specimens from heat B in Fig. 4a), because the hardening introduced during the sample machining could be different. However, at the midlife region, the stress amplitudes for specimens from the same heat are almost the same. Specimens from the same heat exhibit 

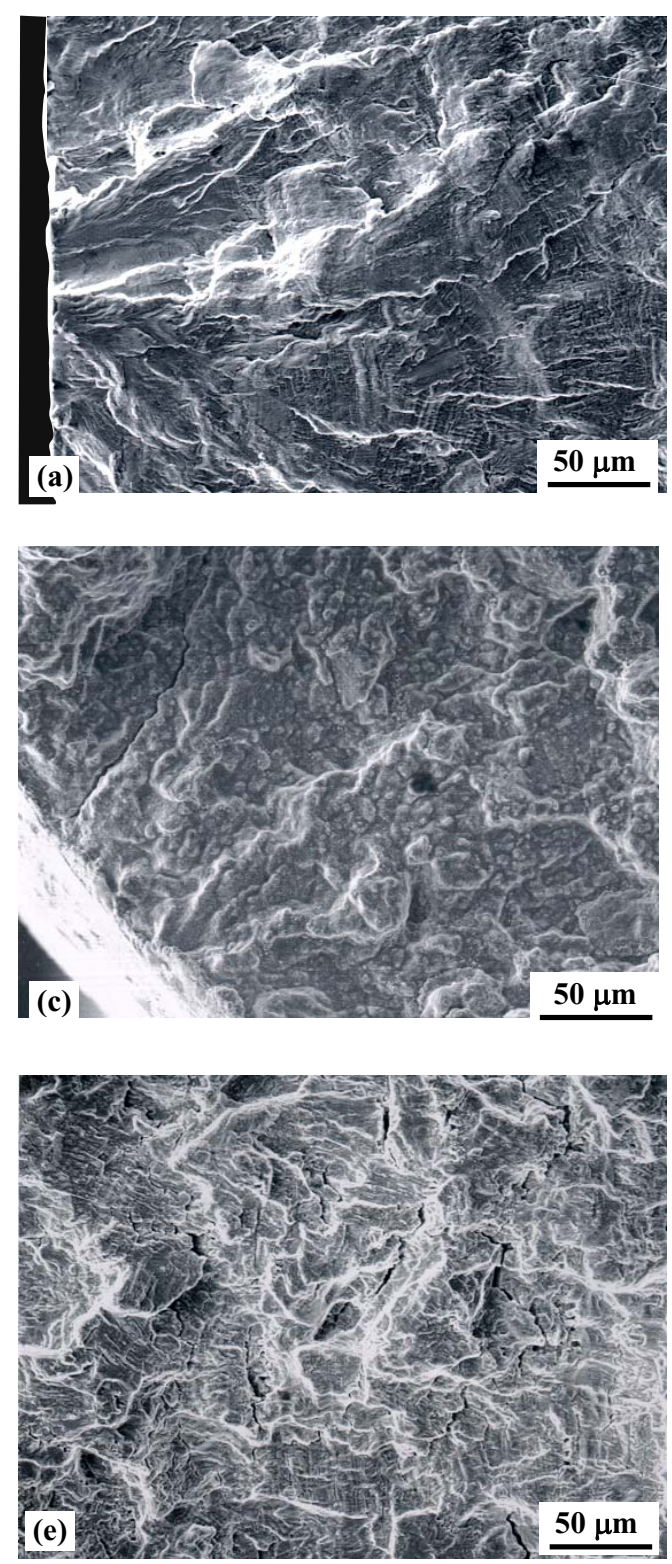
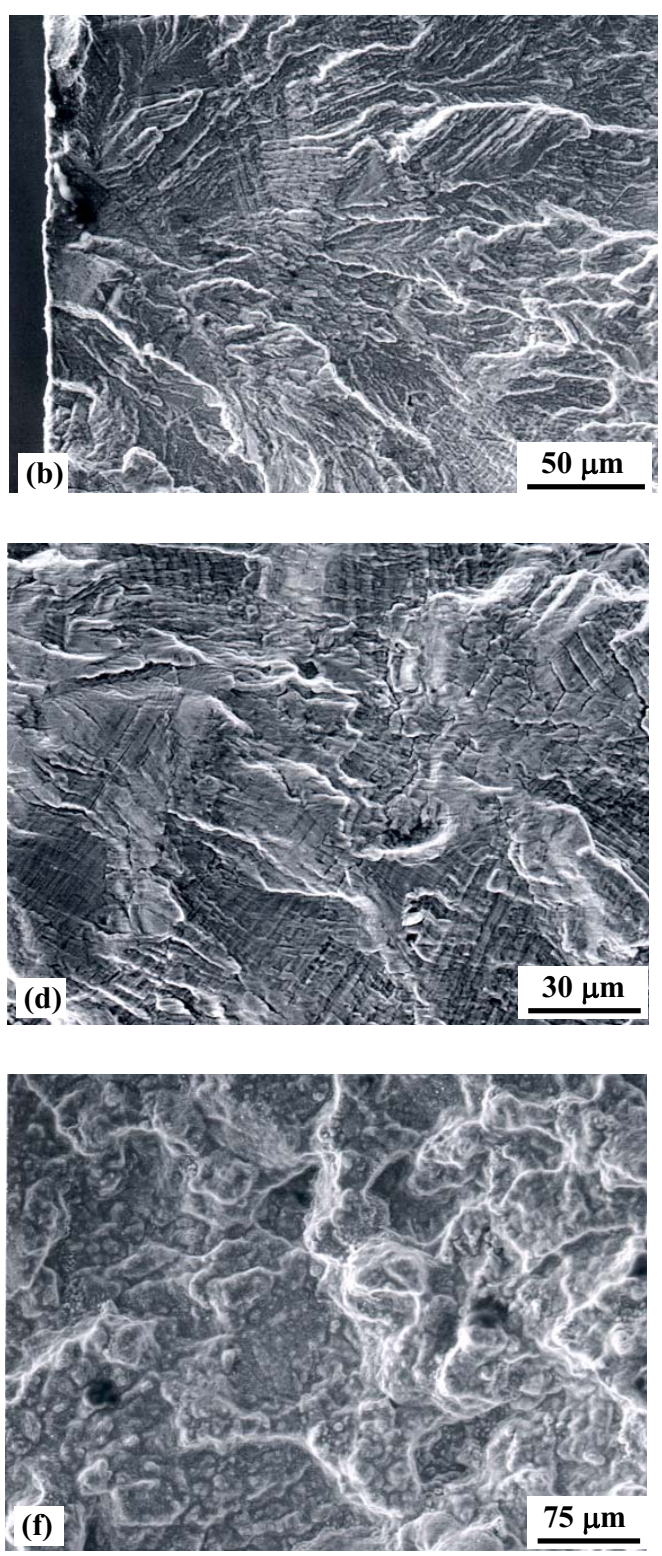

Figure 8. Typical SEM micrographs of fracture surfaces (heat A):

(a) Crack-initiation region $\left(816^{\circ} \mathrm{C}\right.$, without hold times);

(b) Crack-initiation region $\left(927^{\circ} \mathrm{C}\right.$, without hold times);

(c) Crack-initiation region $\left(927^{\circ} \mathrm{C}\right.$, with 10 -min. hold); (d) Crack-propagation region $\left(816^{\circ} \mathrm{C}\right.$, without hold times);

(e) Crack-propagation region $\left(927^{\circ} \mathrm{C}\right.$, without hold times); (f) Crack-propagation region $\left(927^{\circ} \mathrm{C}\right.$, with 10 -min. hold).

very similar cyclic-stress-response behavior. But the cyclicstress response is clearly different for samples from different heats. At $816^{\circ} \mathrm{C}$ without hold time (Fig. 4a), the heat A material shows the highest degree of strain hardening, followed by heat $\mathrm{C}$ and, then, heat B. At $927^{\circ} \mathrm{C}$ with a $10 \mathrm{~min}$. hold time (Fig. 4b), the stress amplitude quickly (within 3 cycles) reaches a maximum and then either saturates (heat $\mathrm{A}$ ) or decreases (heats $\mathrm{B}$ and $\mathrm{C})$.

In an effort to study the hold-time effect on the cyclic stress response, three parameters in the test conditions, i.e., total strain range, hold time, and temperature, were varied. In Figure 5, the total strain range was changed from $0.4 \%$ to $2.0 \%$, the hold time was fixed to $2 \mathrm{~min}$., and the test temperature was kept at $927^{\circ} \mathrm{C}$. Figure 5 contains the same plots as Fig. 3b except for the addition of cyclic-stress-response curves of $2 \mathrm{~min}$. hold-time tests for the various strain levels. The introduction of the $2 \mathrm{~min}$. hold-time decreases the hardening rate and increases the softening rate. Without hold time, the peak-stress amplitude of the test with a $1.0 \%$ total strain range is comparable to that of the test with a total strain range of $1.2 \%$ (as mentioned above), which is unusual. With a 2 min. hold time, this unusual phenomenon is not observed. The peak-stress amplitude of the $1.0 \%$ total-strain-range test is clearly lower than that of the $1.2 \%$ total-strain-range test. 


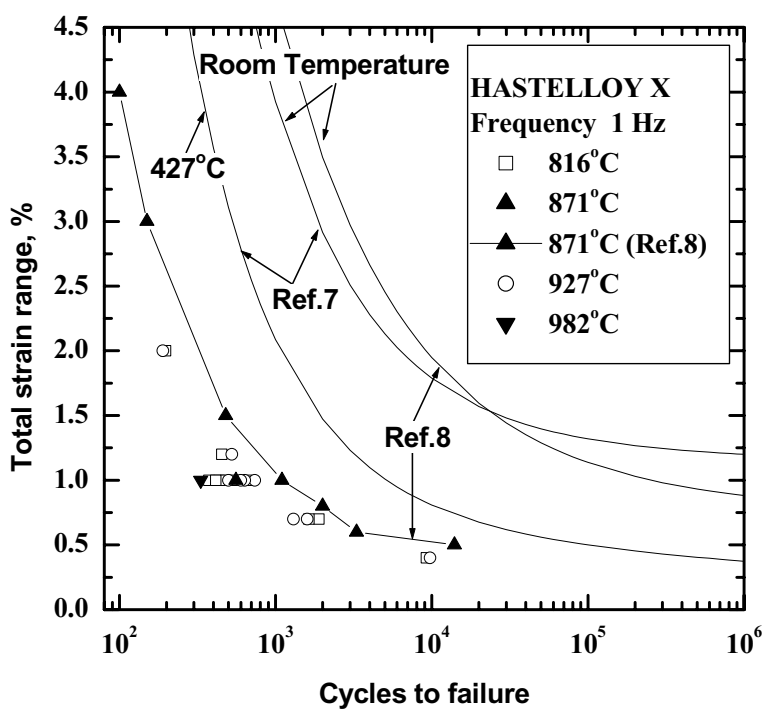

Figure 9. Total-strain range as a function of cycles to failure for low-cycle-fatigue tests without hold times (heats A, B, and C). Data from the literature were also included.

In Figure 6, the hold time was increased from $2 \mathrm{~min}$. to $60 \mathrm{~min}$. with a fixed $1.0 \%$ total strain range, and the temperature was kept at $816^{\circ} \mathrm{C}$ or $927^{\circ} \mathrm{C}$. At $816^{\circ} \mathrm{C}$ (Fig. 6a), the introduction of the $2 \mathrm{~min}$. hold does not change the hardening rate initially. Then, at about 20 cycles, it transforms the stress response from hardening to softening. Further increasing the hold time to 10 min. greatly decreases the hardening rate, and an extended saturation region is observed. The cyclic-stress-response behavior of the $60 \mathrm{~min}$. hold test is similar to that of the $10 \mathrm{~min}$. hold test before around 20 cycles. After 20 cycles, the stress amplitude quickly increases to a maximum and saturates until the final rapid stress drop, resulting in a hump in the curve for the $60 \mathrm{~min}$ hold test.

In Figure 7, the test temperature was varied from $816^{\circ} \mathrm{C}$ to $982^{\circ} \mathrm{C}$ with a $1.0 \%$ total-strain range and $10 \mathrm{~min}$. hold time. The increase of the temperature and the introduction of the $10 \mathrm{~min}$. hold time have similar effects on the cyclic-stress response. They both decrease the hardening rate and increase the softening rate. When the temperature increases to $982^{\circ} \mathrm{C}$ and the $10 \mathrm{~min}$. hold time is imposed, the alloy shows only strain softening and no hardening. For other tests in Fig. 7, the hardening regions are present; the hardening rates are almost the same at the near-start region (within 2 or 3 cycles).

The hardening behavior during cycling may be attributed to the multiplication of dislocations, dislocation-dislocation, and dislocation-precipitate interactions. High densities of dislocations and their interactions would lead to the formation of dislocation jogs and pileups, as well as dislocation tangles around the carbide precipitates, which would be as the barriers to the continued motion of mobile dislocations, and induce hardening. The observed cyclic-softening phenomenon may be generally attributed to the dislocation-recovery effects occurring during strain cycling. The recovery of dislocations is actually a process for dislocations to annihilate and rearrange themselves.

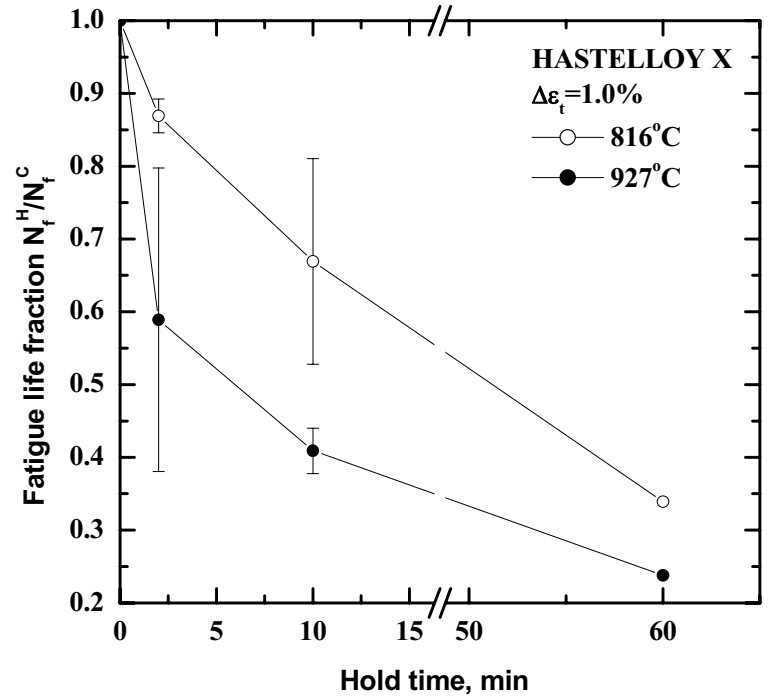

Figure 10. The influence of hold time on the fatigue life at the total strain range of $1.0 \%$ and temperatures of $816^{\circ} \mathrm{C}$ and $927^{\circ} \mathrm{C}$ (heats $\mathrm{A}, \mathrm{B}$, and $\mathrm{C}$ ). Average data and error bars were used when more than one test were conducted.

At the same time, it is also known to be a thermally-active process. Higher temperatures and longer hold times are favorable for the recovery of dislocations. Thus, a dislocation configuration with a lower resistance on the motion of dislocations can be achieved at higher temperatures and longer hold times so that cyclic softening occurs. The saturated cyclicstress response can be considered as a result that the hardening effect from the dislocation multiplication and interaction cancel out the softening effect from the dislocation annihilation and rearrangement.

\section{$\underline{\text { SEM Observations on the Fracture Surfaces }}$}

Except for the final tensile rupture, the fracture of specimens subjected to cyclic deformation generally involves two successive stages. Fatigue cracks firstly initiate and then propagate. For the HASTELLOY X alloy, the microfractographs of the fracture surfaces of the low-cycle-fatigue tested specimens were obtained, using a scanning-electron microscope. For all of the low-cycle fatigue tests with and without hold times, the fatigue cracks were found to originate entirely from the surface of specimens. Under the test conditions used in this investigation, it was observed that the fatigue crack initiates basically in a transgranular mode, as shown in Figures $8 \mathrm{a}, 8 \mathrm{~b}$, and $8 \mathrm{c}$. The scanning-electron micrographs illustrating the nature of the typical crack-propagation region taken from the specimens after low-cycle fatigue tests with and without hold times are given in Figures 8d, 8e, and 8f. For low-cycle fatigue without hold times, the fatigue crack propagated transgranularly, as shown in Figures $8 \mathrm{~d}$ and $8 \mathrm{e}$ at $816^{\circ} \mathrm{C}$ and $927^{\circ} \mathrm{C}$, respectively. At $816^{\circ} \mathrm{C}$, the well-defined fatigue striation could be clearly observed in the crack-propagation region, as shown in Figure 8(d). For low-cycle fatigue tests with hold times, the fatigue crack propagated in a mixed transgranular and intergranular mode, as presented in Figure 8f. Based on this observation, it is suggested that a considerable contribution of the creep damage 

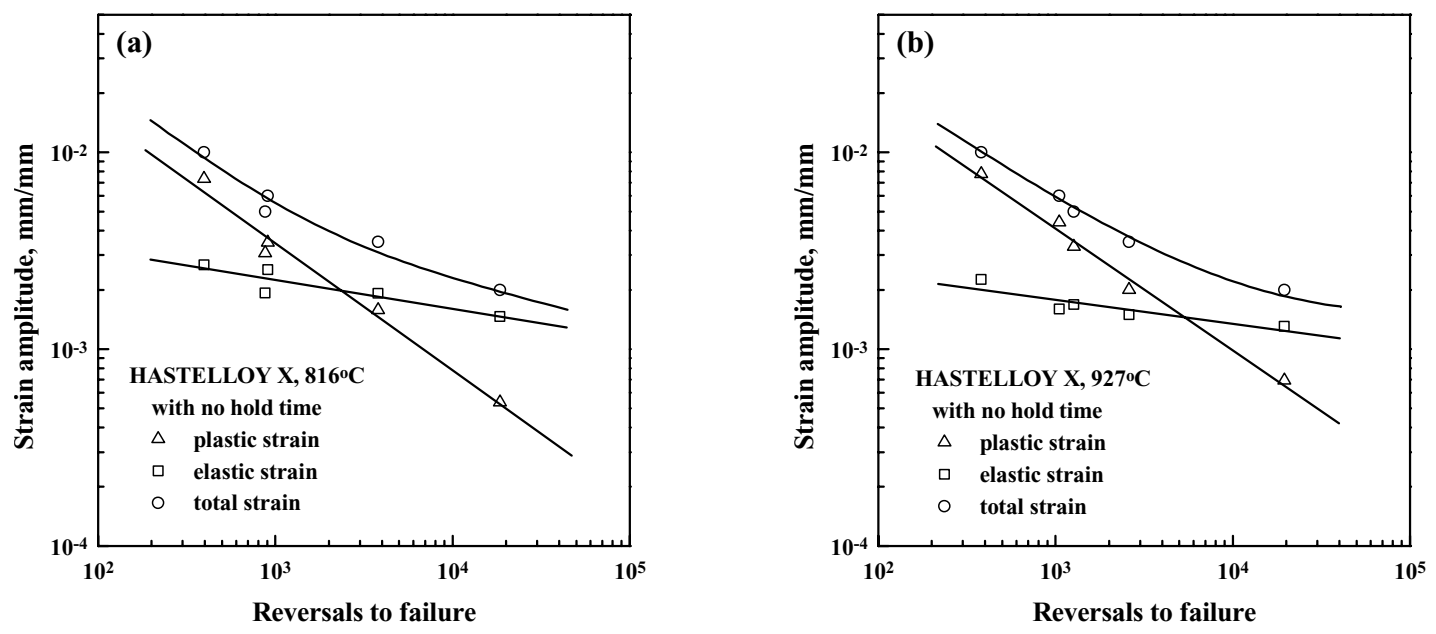

Figure 11. Strain ranges versus cycles to failure curves for low-cycle-fatigue tests without hold times at (a) $816^{\circ} \mathrm{C}$ and (b) $927^{\circ} \mathrm{C}$ (heat A).

is included in the low-cycle fatigue tests with tensile strain hold times. The occurrence of intergranular cracking may also be considered as a consequence of the combined creep and oxidation effects.

\section{Fatigue Life and Cyclic-Stress-Strain Behavior}

The employed total-strain range as a function of the fatigue life for the low-cycle-fatigue tests without hold times is illustrated in Figure 9. Data from the literature [7,8] are also included for comparison. The fatigue life is defined as the number of cycles to failure or specimen rupture. Generally, the fatigue life decreases as the test temperature increases. It can be seen that at all of the total strain ranges used in this investigation, the fatigue life of the alloy is very close to each other at test temperatures from $816^{\circ}$ to $927^{\circ} \mathrm{C}$. It means that for the continuous cycling tests, increasing the test temperature from $816^{\circ} \mathrm{C}$ to $927^{\circ} \mathrm{C}$ has little influence on the fatigue life of the HASTELLOY $\mathrm{X}$ alloy. At $871^{\circ} \mathrm{C}$, the data from this study seem to exhibit a shorter life than those from Ref. 8. When the temperature increases to $982^{\circ} \mathrm{C}$, the fatigue life is clearly shortened.

The relation between the fatigue-life fraction and hold time is shown in Figure 10. The fatigue-life fraction is defined as the ratio of cycles to failure or specimen rupture for the cycling with a hold time $\left(\mathrm{N}_{\mathrm{f}}^{\mathrm{H}}\right.$ ) and for the continuous cycling without hold time $\left(\mathrm{N}_{\mathrm{f}}^{\mathrm{C}}\right.$ ). The low-cycle fatigue life was found to decrease at two test temperatures due to the introduction of a tensile strain hold time. At both temperatures, the fatigue life showed a monotonic decrease with increasing the hold time.

For those low-cycle-fatigue tests without hold times, because the cyclic frequency is relatively high so that the time spent at the high temperature is shorter, the difference in the effect of oxidation damage at different test temperatures can be neglected. On the other hand, it can be considered that the creep damage from $816^{\circ} \mathrm{C}$ to $927^{\circ} \mathrm{C}$ is comparable because the resistance of HASTELLOY $\mathrm{X}$ on creep deformation is still excellent in the present temperature range investigated [9].
Moreover, the fractographic study shows that there is no drastic change in the rupture mode from a transgranular to intergranular type, while the intergranular fracture is usually considered as a direct verification that the creep-fatigue interaction happens. The above fact implies that at temperatures from $816^{\circ} \mathrm{C}$ to $927^{\circ} \mathrm{C}$, the difference in creep damage is not significant. Thus, there is almost no difference in the fatigue life of the alloy at test temperatures from $816^{\circ} \mathrm{C}$ to $927^{\circ} \mathrm{C}$.

Although the deleterious influence of temperature on the lowcycle fatigue life in this investigation is negligible under a continuous cycling condition, the effect of oxidation damage will become very significant if a hold time is introduced, since the longer time would be spent at high temperatures. Thus, the alloy exhibits the shorter fatigue life due to the introduction of the hold time. The stress relaxation that occurs during hold time results in the development of the creep strain and increases the accumulated strain in the crack-tip region, which will induce intergranular crack growth and promote the propagation of a fatigue crack, and lead to a decrease in the fatigue life. It can be concluded that the combination of oxidation and creep damages will lead to a substantial reduction of the fatigue life in lowcycle-fatigue tests with tensile hold times.

For total strain-controlled low-cycle fatigue tests without hold times, a better knowledge of the fatigue-life behavior of metallic alloys is generally obtained by separating the total strain amplitude into the plastic and elastic strain amplitudes. Based on the well-known Coffin-Manson equation, the relationship between the total strain amplitude and fatigue life can be expressed as

$$
\frac{\Delta \varepsilon_{\mathrm{t}}}{2}=\frac{\Delta \varepsilon_{\mathrm{p}}}{2}+\frac{\Delta \varepsilon_{\mathrm{e}}}{2}=\varepsilon_{\mathrm{f}}^{\prime}\left(2 \mathrm{~N}_{\mathrm{f}}\right)^{\mathrm{c}}+\frac{\sigma_{\mathrm{f}}^{\prime}}{\mathrm{E}}\left(2 \mathrm{~N}_{\mathrm{f}}\right)^{\mathrm{b}}
$$

where $\Delta \varepsilon_{\mathrm{t}} / 2, \Delta \varepsilon_{\mathrm{p}} / 2$, and $\Delta \varepsilon_{\mathrm{e}} / 2$ are the total, plastic, and elastic strain amplitudes, respectively, $2 \mathrm{~N}_{\mathrm{f}}$ is the number of reversals to failure, $\mathrm{E}$ is Young's modulus, and $\varepsilon_{\mathrm{f}}^{\prime}, \mathrm{c}, \sigma_{\mathrm{f}}^{\prime}$, and $\mathrm{b}$ are the fatigue-ductility coefficient, fatigue-ductility exponent, fatigue-strength coefficient, and fatigue-strength exponent, 
Table 2. Strain fatigue parameters of HASTELLOY X (heat A) at $816^{\circ} \mathrm{C}$ and $927^{\circ} \mathrm{C}$

\begin{tabular}{cccccccc}
\hline $\begin{array}{c}\text { Temperature } \\
\left({ }^{\circ} \mathrm{C}\right)\end{array}$ & $\begin{array}{c}\sigma_{f}^{\prime} \\
(\mathrm{MPa})\end{array}$ & $b$ & $\begin{array}{c}\varepsilon_{f}^{\prime} \\
(\%)\end{array}$ & $c$ & $\begin{array}{c}\underline{\mathrm{K}}^{\prime} \\
(\mathrm{MPa})\end{array}$ & $n^{\prime}$ & $N_{t}$ \\
\hline 816 & 960.8 & -0.1448 & 28.2 & -0.6384 & 687.2 & 0.1499 & 1,183 \\
927 & 613.4 & -0.1236 & 29.4 & -0.6185 & 382.0 & 0.0993 & 2,665 \\
\hline
\end{tabular}

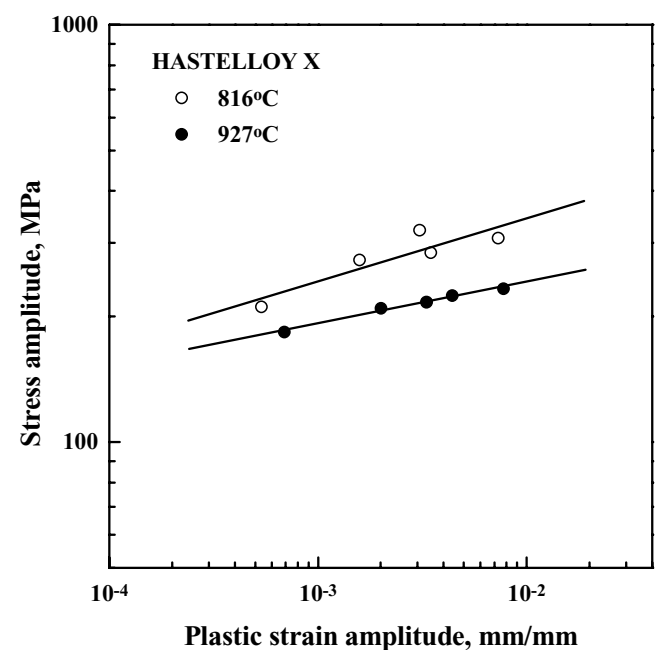

Figure 12. Cyclic-stress amplitude as a function of the plastic-strain amplitude for low-cycle-fatigue tests without hold times at $816^{\circ} \mathrm{C}$ and $927^{\circ} \mathrm{C}$ (heat A).

respectively. For the low-cycle fatigue tests without hold times, the bilogarithmic curves of total, plastic, and elastic strain amplitude versus reversals to failure at $816^{\circ} \mathrm{C}$ and $927^{\circ} \mathrm{C}$ are shown in Figures 11a and 11b. The plastic and elastic strain amplitudes are obtained at half of the fatigue life. For the lowcycle fatigue tests without hold times, the strain-fatigue life data is analyzed, using the apparent linear fit program according to Equation (1). The results of the analyses are given in Table 2. It can be noted that the values of $\mathrm{b}$ and $\mathrm{c}$ increase with increasing the temperature from $816^{\circ} \mathrm{C}$ to $927^{\circ} \mathrm{C}$, even though for each parameter, the difference at two temperatures is not very significant. Moreover, it is also found that with increasing temperature, $\sigma_{f}^{\prime}$ decreases, while there is almost no obvious change in $\varepsilon_{f}^{\prime}$.

The transition fatigue life, $\mathrm{N}_{\mathrm{t}}$, the number of cycles at which the elastic and plastic strain amplitude is equal, can be obtained from Figures $11 \mathrm{a}$ and $11 \mathrm{~b}$. The typical values of $\mathrm{N}_{t}$ at both temperatures of $816^{\circ} \mathrm{C}$ and $927^{\circ} \mathrm{C}$ are also listed in Table 2. It is noticeable that the transition fatigue life shifts to higher values with increasing the temperature from $816^{\circ} \mathrm{C}$ to $927^{\circ} \mathrm{C}$. As suggested by Coffin [10], the transition fatigue life of materials is related to its strength and ductility. Generally, the material with high strength and low ductility will exhibit a shorter transition-fatigue life. Based on the tensile properties given in Ref. 9, with increasing the temperature from $816^{\circ} \mathrm{C}$ to $927^{\circ} \mathrm{C}$, the alloy shows a lower strength though the elongation does not change too much. Thus, it should be reasonable that the longer transition-fatigue life is observed at $927^{\circ} \mathrm{C}$ than at $816^{\circ} \mathrm{C}$.

The cyclic stress-strain curves of the alloy at $816^{\circ} \mathrm{C}$ and $927^{\circ} \mathrm{C}$ for low-cycle fatigue tests without hold times are depicted in Figure 12. The stress amplitude is taken at half of the fatigue life. The variation of the stress amplitude with the plastic strain amplitude is usually represented by Holloman equation:

$$
\frac{\Delta \sigma}{2}=K^{\prime}\left(\frac{\Delta \varepsilon_{p}}{2}\right)^{n^{\prime}}
$$

where $\Delta \sigma / 2$ represents the cyclic-stress amplitude at half life, $\mathrm{K}^{\prime}$ is the cyclic-strength coefficient, and $\mathrm{n}^{\prime}$ is the cyclicstrength exponent. Using an apparent linear-fit program, the cyclic stress-strain data in the present experiment is analyzed according to Equation (2). The derived values of $\mathrm{K}^{\prime}$ and $\mathrm{n}^{\prime}$ are given in Table 2. It is obvious that both $\mathrm{K}^{\prime}$ and $\mathrm{n}^{\prime}$ decrease with increasing temperature.

\section{Fatigue-Life Prediction}

Ostergren [11] suggested that the hysteresis energy associated with the plastic deformation is a measure of the damage inside the materials subjected to cyclic loading and can be used as a damage function to predict the fatigue life. The hysteresis energy per cycle is defined as the mechanical energy absorbed per unit volume during one cycle, and given by the area of the stress-strain hysteresis loop. It has been indicated that most of the cycles required to fail a smooth specimen are involved in propagating a micro-scale crack to a critical size. In fact, only the deformation occurring in the tensile portion of the cycle with the crack open can contribute to the damage by propagating the crack. No localized damage from the deformation in the compressive portion of the cycle should take place due to crack closure. It means that the direct measure of damage during cycling deformation would be the deformation to propagate the fatigue crack. Thus, it should be reasonable to postulate the tensile hysteresis energy as a measure of fatigue damage. Ostergren [11] proposed that the tensile-hysteresis energy, $\Delta \mathrm{W}_{\mathrm{T}}$, per cycle can be approximated by the product of the inelastic strain range, $\Delta \varepsilon_{i n}$, and the maximum tensile stress, $\sigma_{\mathrm{T}}$, that is:

$$
\Delta \mathrm{W}_{\mathrm{T}}=\sigma_{\mathrm{T}} \cdot \Delta \varepsilon_{\text {in }}
$$

The calculated tensile-hysteresis energy using Equation (3) is compared with that measured at the half-lives of the low-cycle fatigue tests without hold times conducted. It is found that if Equation (3) is used to calculate the tensile-hysteresis energy per cycle, an overestimated value will be obtained at both 

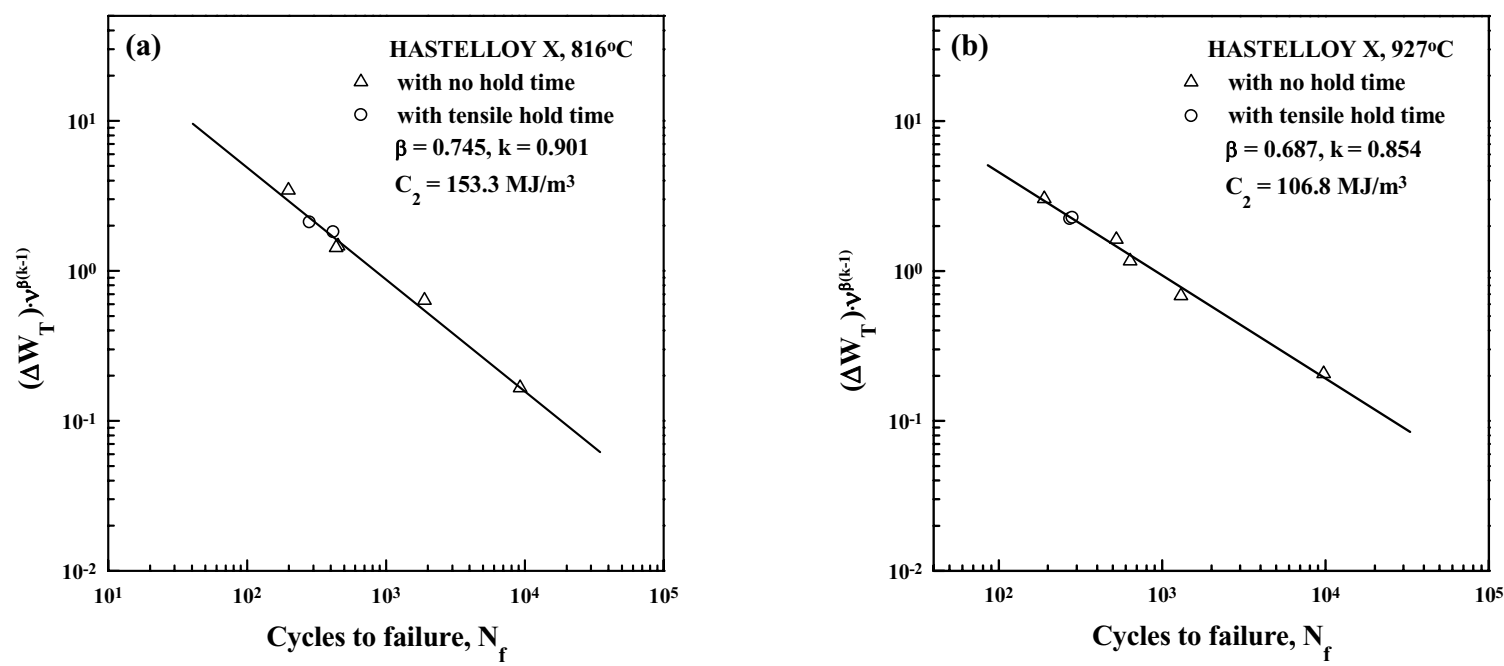

Figure 13. Relationship between the frequency-modified tensile-hysteresis energy and cycles to failure for low-cycle tests with and without hold times at (a) $816^{\circ} \mathrm{C}$ and (b) $927^{\circ} \mathrm{C}$ (heat A).

temperatures of $816^{\circ} \mathrm{C}$ and $927^{\circ} \mathrm{C}$. This fact indicates that it is necessary to incorporate a numerical constant to modify the Equation (3). If a constant, $\left(1-n^{\prime}\right) /\left(1+n^{\prime}\right)$, used by Halford [12] to determine the average total energy per cycle, is incorporated into Equation (3), it is found that the calculated tensile-hysteresis energies are closer to the measured values. Thus, the following equation will be used to approximate the tensile-hysteresis energy per cycle for the low-cycle-fatigue tests with and without hold times, that is:

$$
\Delta \mathrm{W}_{\mathrm{T}}=\sigma_{\mathrm{T}} \cdot \Delta \varepsilon_{\text {in }}\left[\frac{\left(1-\mathrm{n}^{\prime}\right)}{\left(1+\mathrm{n}^{\prime}\right)}\right]
$$

where $\mathrm{n}^{\prime}$ is the cyclic-strain-hardening exponent, and can be obtained from the above-mentioned Holloman equation.

By substituting the inelastic-strain component with the tensilehysteresis energy in the Coffin-Manson equation with the form of $\Delta \varepsilon_{\text {in }} \cdot\left(\mathrm{N}_{\mathrm{f}}\right)^{\alpha}=\mathrm{C}$, one can obtain

$$
\Delta \mathrm{W}_{\mathrm{T}} \cdot\left(\mathrm{N}_{\mathrm{f}}\right)^{\beta}=\mathrm{C}_{1}
$$

where $\mathrm{N}_{\mathrm{f}}$ is the number of cycles to failure, and $\alpha$ and $\mathrm{C}_{1}$ are the material constants.

To take account of the time-dependent damage, a frequencymodified term should be introduced into Equation (5). Similar to Coffin's frequency-modified equation, the relationship between the frequency-modified tensile-hysteresis energy and cycles to failure can be expressed as

$$
\Delta \mathrm{W}_{\mathrm{T}} \cdot\left(\mathrm{N}_{\mathrm{f}} \cdot v^{\mathrm{k}-1}\right)^{\beta}=\mathrm{C}_{2}
$$

where $\mathrm{k}$ and $\mathrm{C}_{2}$ are material constants, and $v$ is the cyclic frequency, defined as

$$
v=\frac{1}{\tau_{c}+\tau_{h}}
$$

where $\tau_{\mathrm{c}}$ is the time for continuous cycling, and $\tau_{h}$ the hold time per cycle. It needs to be pointed out that at the cyclic frequency of $1 \mathrm{~Hz}$, two constant terms in Equations (5) and (6), $\mathrm{C}_{1}$ and $\mathrm{C}_{2}$, should have the same value.

If the frequency-modified tensile-hysteresis energy as a function of cycles to failure for the low-cycle fatigue tests with and without hold times at $816^{\circ} \mathrm{C}$ is plotted, it can be seen that all data points fall on a common straight line, as shown in Figure 13a. The same case is also noted at $927^{\circ} \mathrm{C}$, as presented in Figure 13b. It means that the frequency-modified tensilehysteresis-energy method can correlate the high-temperature strain-fatigue-life data.

For all of the low-cycle-fatigue tests with and without hold times performed at $816^{\circ} \mathrm{C}$ and $927^{\circ} \mathrm{C}$, a comparison of the predicted life, based on Equation (6), with the measured one reveals a good correlation between the two, as shown in Figure 14. This fact suggests that the fatigue life of the HASTELLOY X alloy can be predicted reasonably well using the frequency-modified tensile-hysteresis energy as a damage function.

\section{Conclusions}

Based on the above analyses and discussions, some conclusions can be made:

1. In the total-strain ranges used in this investigation, increasing the test temperature from $816^{\circ} \mathrm{C}$ to $927^{\circ} \mathrm{C}$ has no significant influence on the fatigue life. However, increasing the temperature from $927^{\circ} \mathrm{C}$ to $982^{\circ} \mathrm{C}$ clearly shortened the fatigue life.

2. Introducing hold times at the maximum tensile strain is found to lead to a significant reduction in the fatigue life.

3. The HASTELLOY X alloy can exhibit cyclic hardening, cyclic hardening followed by softening or the saturated 

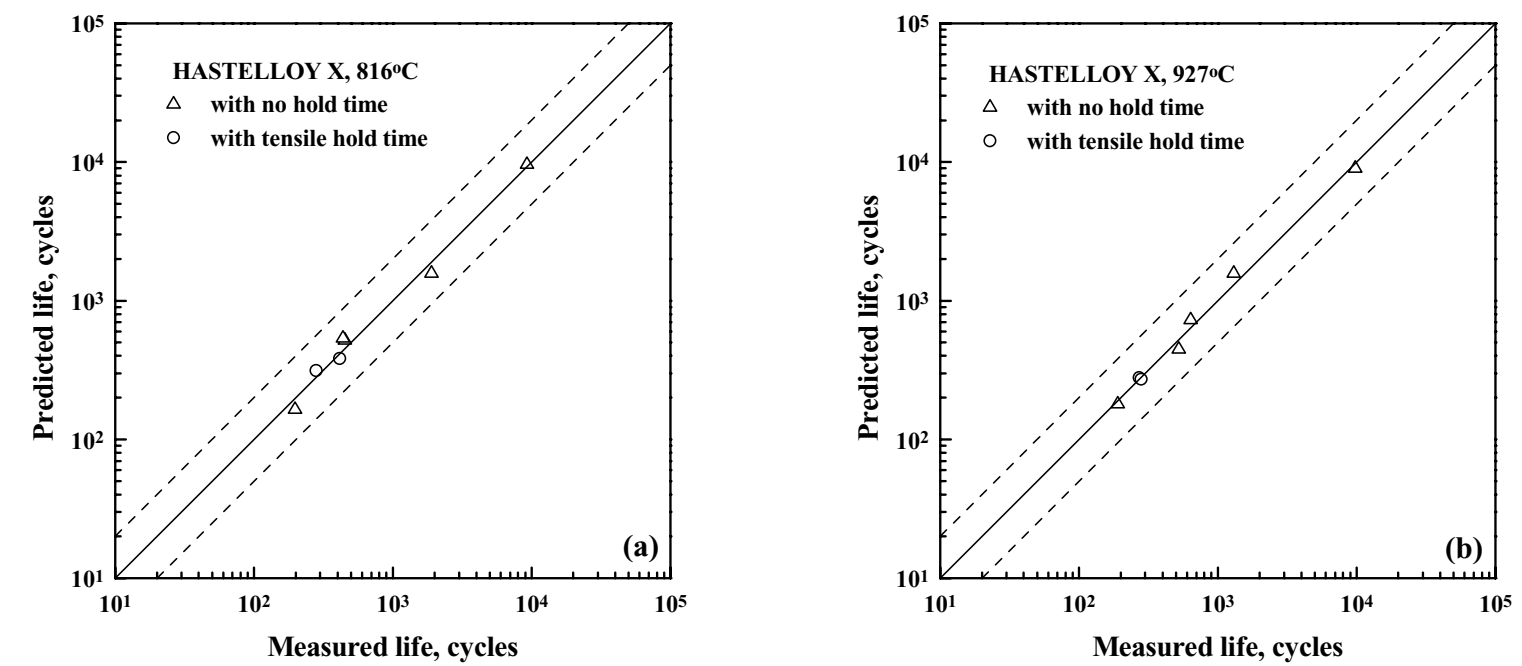

Figure 14. Fatigue-life prediction using the frequency-modified hysteresis-energy method for low-cycle-fatigue tests with and without hold times at (a) $816^{\circ} \mathrm{C}$ and (b) $927^{\circ} \mathrm{C}$ (heat A).

stress response, and cyclic softening during low-cycle fatigue deformation, which is closely related to the test temperature, the imposed total strain range, and the hold time.

4. The HASTELLOY $X$ alloy shows the heat-to-heat variation in the cyclic stress response curve.

5. Under the low-cycle fatigue test conditions, a fatigue crack is found to initiate in a transgranular manner. The fatiguecrack propagation occurs in a transgranular or mixed transgranular and intergranular mode, which mainly depends on whether the hold time is introduced at the maximum tensile strain.

6. The frequency-modified tensile-hysteresis-energy method can give satisfactory predictions of the fatigue lives for the nickel-based superalloy, HASTELLOY $X$, in hightemperature, low-cycle fatigue tests with and without hold times.

\section{Acknowledgements}

This work is supported by the Solar Turbines Inc., Haynes International, Inc., the University of Tennessee, the U. S. Department of Energy's Advanced Turbine Systems Program, the National Science Foundation (NSF), under Grant No. DMI9724476, the NSF Combined Research-Curriculum Development Program, under EEC-9527527, the NSF Integrative Graduate Education and Research Training (IGERT) Program, under DGE-9987548, and the NSF International Materials Institutes (IMI) Program, under DMR-0231320, with Dr. D. Durham, Dr. M. Poats, Ms. W. Jennings, Dr. L. Goldberg, and Dr. C. Huber as contract monitors.

\section{References}

1. Klarstrom, D. L., and Lai, G. Y., 1988, "Effects of Aging on the LCF Behavior of Three Solid-Solution-Strengthened Superalloys," Superalloys 1988, S. Reichman, D. N. Duhl, G. Maurer, S. Antolovich, and C. Lund, eds., The Metallurgical Society/AIME, PA: Champion, pp. 585-594
2. Miner, R. V. and Castelli, M. G., 1992, "Hardening Mechanisms in a Dynamic Strain Aging Alloy, HASTELLOY $X$, During Isothermal and Thermomechanical Cyclic Deformation," Metallurgical Transactions A, Vol. 23A, pp. 551-561.

3. Seaver, D. W., 1979, "Low Cycle Fatigue Properties of Hastelloy X at $704^{\circ} \mathrm{C}\left(1300^{\circ} \mathrm{F}\right)$," Methods for Predicting Material Life in Fatigue, New York, pp. 133-144.

4. Tsuji, H. and Kondo, T., 1987, "Strain-Time Effects in Low-Cycle Fatigue of Nickel-Base Heat-Resistant Alloys at High Temperature," Journal of Nuclear Materials, Vol. 150, pp. 259-265.

5. Hour, K. Y. and Stubbins, J. F., 1990, "Crack Growth Behavior and Failure Micromechanisms in Three Heat Resistant Materials at Elevated Temperature," Acta Metallurgica et Materialia, Vol. 38, pp. 1463-1474.

6. Tawancy, H. M., 1983, "Long-Term Ageing Characteristics of Hastelloy Alloy X," Journal of Materials Science, Vol. 18, pp. 2976-2986.

7. Cabot Technical Report for High Performance Wrought Alloy, "Fatigue Information of Several Nickel Based Alloys," Literature Obtained from Haynes International.

8. McCoy, H. E., Strizak, J. P., and King, J. F., 1984, "HASTELLOY X for High-Temperature Gas-Cooled Reactor Applications," Nuclear Technology, Vol. 66, pp. 161-174.

9. Haynes International Technical Bulletin H-3009A, HASTELLOY® X Alloy.

10. Coffin, L. F., Jr., 1972, "Fatigue at High Temperature," Fatigue at High Temperature, A. E. Carden, A. J. McEvily, and C. H. Wells, eds., ASTM STP 520, Philadelphia, pp. 534.

11. Ostergren, W. J., 1976, “A Damage Function and Associated Failure Equations for Predicting Hold Time and Frequency Effects in Elevated Temperature Low Cycle Fatigue," Journal of Testing and Evaluation, Vol. 4, pp. 327-339.

12. Halford, G. R., 1966, "The Energy Required for Fatigue", Journal of Materials, Vol. 1, pp. 3-18. 